\title{
(Re-)nostalgização: o cinema de Macau enquanto construção da identidade
}

\author{
(Re)nostalgization: Macau's cinema as a construct of identity \\ Cheong Kin Man \\ Institut für Ethnologie, Freie Universität Berlin
}

\begin{abstract}
The officially hinted yet unofficial discourse of "Macau-Was-Never-A-Colony" challenges postcolonial studies all hiddenly and mute(d)ly. Its rare presence in the non-Sino-Luso-academic world explains its legitimate absence. The multi-centenary Portuguese presence in or colonization of Macau marked only its attachedness to the verges of Empires. From its transitional period in the last stage of the Portuguese Empire to its self-governance under the much larger Chinese context, Macau, or better say, its name and its appearance, was no more than a short-term machine of nostalgia. In this background, the emergence of Macau cinema from the last colonial times until its present contributes to a discourse towards the production of an identity, whose future is still unknown. The proposed essay questions precisely this role of Macau cinema in this process of (re)nostalgization in the coming decades until 2049, the end of a promise of two powers that decided its 50-year long would-be future, two-fifths of which has already passed.
\end{abstract}

Keywords: Macau, China, nostalgization, cinema, identity

\section{“Indescolonizabilidade" de uma não-colónia}

Escrevendo em língua portuguesa, considero que a palavra Macau faz parte integrante do vocabulário desse idioma. Macau é, naturalmente, parte integral de uma globalidade de estudos em Portugal a que eu chamaria, numa perspectiva estrangeira, estudos portugueses. Esses estudos estão ligados à perpetuação da existência de um império "desimperializado" em que Portugal e a Lusofonia funcionam como um mundo de língua portuguesa pós-colonial.

Paralelamente ao grande espólio destes estudos em português sobre Macau, enquanto herança colonial ou como prolífico meio de servir a academia lusófona contemporânea, existem igualmente, do lado do território ex-colonial ou ex-administrado por um país estrangeiro, estudos de Macau produzidos em Macau, contando mesmo com a eufórica criação de uma "Macaulogia" (com um "u", se tomarmos como base a grafia portuguesa) ou "Macaology" (com um "o" se tomarmos como base a grafia inglesa).

Neste plano, Macau torna-se o centro dos seus próprios estudos no contexto mais vasto da República Popular da China, sendo um território autónomo com algum estatuto internacional. $\mathrm{O}$ discurso de que "Macau nunca foi uma colónia" como subproduto da negociação entre uma potência mundial em ascensão, a China, e uma ex-potência cuja glória expansionista já pertence ao passado, oferece-se como um pré-requisito para os mencionados estudos, quer lusófonos, quer sinófonos, para o enquadramento do contexto, tanto em termos académicos ou num âmbito mais amplo, ou seja, no entendimento geral.

Macau, entretanto, permanece tema de estudos regionais, restritos em termos geográficos. Estão em causa duas civilizações com as suas próprias geografias, a ocidental de que Portugal faz parte, e a chinesa. Um estudo de antropologia (somente visual ou não), ou mesmo multidisciplinar, não implica a superioridade de uma civilização, uma vez que, como sempre, a própria antropologia ainda está sujeita a uma abordagem hierárquica. Por exemplo, parece poder apenas ter autoridade para incorporar os temas relativamente menores, enquanto os temas maiores sobre as civilizações têm as suas próprias disciplinas criadas com a geografia e e que têm autoridade académica própria.

Num artigo que assinei com Schmidt
(2020), intitulado "Dekolonialisierung des Undekolonialisierbaren durch Bewegtbild: Macau", descrevemos como um poder colonial (Portugal) e um outro poder em (re)ascensão para o lugar de potência mundial (a China) concordaram quase ao mesmo tempo, mas por iniciativas próprias e com motivos diferentes, em conferir a uma colónia (Macau) - que já não era bem uma colónia - um estatuto não-colonial ou mesmo descolonizá-la. Apesar de tal poder até contribuir para uma teorização interessante em termos académicos, os estudos sobre Macau têm ficado limitados a uma área geográfica restrita, como referi. Assim sendo, as forças categorizadoras, quer no interior do mundo académico, quer no exterior desse mundo, parecem continuar a conduzir e de certa forma também a controlar os interesses no progresso do conhecimento científico.

Escrevo aqui enquanto falante de português como língua estrangeira e natural de Macau. Obviamente, isso contribui para uma afectividade preconceituosa ou parcialidade afectiva. Porém, em vez de me enquadrar na euforia dos estudos de Macau, remeto-me para uma certa frustração ao observar a escassíssima visibilidade e o fraquíssimo interesse por esta entidade geográfica e política no mundo. A minha auto-complacência em justificar a importância teórica de Macau, na esperança de traduzir esta ideia em várias outras línguas e num contexto cultural e politicamente afastado dessa região, deriva não 
apenas do meu afecto enquanto preconceito. Resulta igualmente do potencial deste caso, "trabalhável" num âmbito mais alargado e em campos muito diversos como, por exemplo, o do estudos sobre o pós-colonialismo ou o da antropologia visual.

Passo a ilustrar o processo da descolonização de Macau:

1. Definindo a colónia como uma província ultramarina, o próprio Portugal colonial excluiu oficialmente Macau da sua lista de colónias já na primeira metade do século passado, ao mesmo tempo que as elites de origem chinesa cessavam progressivamente de se identificar como "chineses no estrangeiro";

2. A retirada de Macau da lista de colónias das Nações Unidas foi realizada em 1972 por iniciativa da República Popular da China, três anos antes da aprovação do Estatuto Orgânico de Macau por parte de Portugal, e que definiu Macau como "território chinês sob administração portuguesa";

3. Na Declaração Conjunta assinada pelos dois países em 1987 existe o termo "transição" (1987-1999), mas raramente se fala no discurso público actual da segunda "transição" (1999-2049), na qual Macau funciona como uma entidade oficialmente auto-governada e em que não há uma definição clara quanto ao futuro de Macau para além de 2049.

Continuo na minha frustrante euforia: definir o que é uma colónia, um território ocupado por um país estrangeiro ou ainda um território sob administração estrangeira, situação proporcionada durante e pelas relações históricas entre um país que é um legítimo representante do Ocidente e por um outro que sofreu uma ocidentalização mais ou menos voluntariamente forçada e que, actualmente, é já a segunda maior economia mundial. Tal parece constituir não apenas um caso potencialmente curioso para os estudos pós-coloniais, tornando igualmente urgente discutir a sua incorporação ou não no corpo global das teorias da antropologia existentes.

A par destas definições, constata-se que, durante todo o processo, os dois poderes sempre negociaram até poderem concordar numa reencarnação da herança colonial descolonizada como fruto do intercâmbio intercultural e inter-civilizacional, um desfecho feliz que curiosamente as três administrações - o antigo administrador (Portugal), o soberano (a China) e o auto-administrador (Macau no maior contexto chinês) - se contentam em reclamar.

Neste contexto, a herança audiovisual e a nostalgia (agora institucionalmente) produzida por meio de cinema com a finalidade de criar uma constantemente renovada identidade regional contribuem apenas para uma maior complexidade teórica, uma vez que o próprio cinema oferece um ecossistema de categorização que foge um pouco ao enquadramento em termos geográficos. Neste ensaio, ou nesta experimentação textual, pretendo justamente observar uma constante "nostalgização" do cinema no mais amplo sentido e, ao apresentar alguns factos mais ou menos empíricos - o menos possível -, propor um ponto de vista no intuito de levar o tema Macau a fugir da sua geografia restrita, e a deixar, portanto, a sua obscuridade teórica.

\section{Contar uma História sem factos}

É, de certa forma, ao serviço do capitalismo intelectual que escrevo aqui sobre Macau e o seu cinema. O tema em si, desta entidade política existente dentro das suas fronteiras físicas, parece ser superior aos interesses da ou à vontade de servir a academia. Paradoxalmente, é justamente ao pensar assim que a academia pode demonstrar a sua mais-valia para um estudo, que não tem mais do que o objectivo de contar uma História com letra maiúscula. Neste caso, uma História a considerar o elemento auto-etnográfico, em vez de uma História concebida como quem fabrica um Deus omnipresente (o que, embora seja uma hábito ou convenção feliz, não é a opção deste meu modesto ensaio). Proponho uma História que não seja somente um somatório de elementos e referências bibliográficas. Proponho também incluir na História uma visão do mundo, neste caso de forma auto-etnográfica.

O lado perverso dos seres humanos tem feito com que muitas palavras sejam substituídas por outras. As palavras são alternadas, mas o que está atrás delas permanece o mesmo. Simultaneamente, vários sistemas de pensar e de categorizar têm contribuído para uma enorme complexidade na interpretação das palavras. Um exemplo é o do tema "colonialismo", que implica uma crueldade extrema infligida a seres humanos e que agora tende a ser reconhecido (ou rejeitado) segundo muitas maneiras de categorizar que, embora diversas, têm que ver com uma origem ocidental, reinventada e reapropriada para os seus próprios usos nas culturas que se contentam em identificar-se como "não-ocidentais".

A maior ironia é que, embora eu defenda as fronteiras físicas existentes em Macau, fantasio um mundo estruturado com menos categorias e, sobretudo, menos fronteiras políticas ou intelectuais. Nesta visão inventada com as categorias existentes, sinto-me obrigado a expor as minhas preocupações questionando se a vitimização (julgada "justificável" ou não) está a ser utilizada como estratégia de produção de conhecimento ou se me devo proibir de pensar desta forma. A vitimização (julgada "justificável" ou não) no contexto de (pós)colonialismo ainda pode ser válida no presente quando as categorias de origem ocidental deixam de existir. Julgo que qualquer espécie de assimetria de poder ou opressão deve ser necessariamente bem discutida, seja essa considerada "estrangeira" ou "doméstica".

Ora, Macau parece um oásis na teoria do colonialismo, se continuarmos aqui com as mencionadas categorias, às quais estamos demasiado habituados. Vários discursos públicos fabricados 
durante várias fases políticas, e que atravessaram vários períodos históricos, sempre defenderam - e naturalmente o presente discurso público também defende - que "Macau nunca foi uma colónia".

Macau parece ter legitimidade para fugir da teoria tanto quanto o seu estatuto como antiga colónia é reconhecido ou rejeitado. Ao mesmo tempo, neste contexto maior, a auto-representação audiovisual, como muitas outras formas de representação, acontece de forma muito semelhante ao que aconteceu com a criação da própria Região Administrativa Especial de Macau: ouve-se sublinhar o facto de que agora as Histórias são contadas pelos seus próprios contadores de Histórias. Com excepção das várias Histórias oficiosamente consideradas tabus na vida pública, a incorporação da herança em geral numa feliz diversidade prova, de novo, que Macau é um caso singular.

Curioso é que a brutalidade não existiu nos moldes em que se verificou em muitas colónias "clássicas". Excluindo as considerações políticas de eliminar a palavra "colónia" no contexto de Macau, parece que não há necessidade de ver o colonialismo de Macau como algo que é necessário esconder com uma mudança de palavra. Até pode ser útil conservar esses termos, para proveito de uma maior proliferação de teorias no contexto internacional.

Talvez seja justamente nesta feliz diversidade que Macau e as suas formas de representação, incluindo o cinema, convirjam para um outro pólo da vitimização (julgada "justificável” ou não): a euforia (julgada "justificável" ou não), na qual aparentemente a abordagem de problemas não parece encorajada institucionalmente e todas as representações parecem dever servir a euforia de forma directa e imediata, embora tal comporte o risco de fazer com que essas representações se tornem meramente instrumentais e válidas no curto prazo.

Ainda assim, tal surge-me igualmente associado ao potencial risco de instrumentalização ou mecanização da vitimização (julgada "justificável” ou não) noutro pólo de produção de conhecimento. Não admira que esta dicotomia ofereça um contraste com as origens históricas destes dois pólos. No âmbito da imensa vaga actual de descolonização pós-moderna no mundo, levanto de novo a questão que levantámos naquele ensaio de 2020, mas aqui colocada de uma outra forma: seria ainda teoricamente interessante uma tal "descolonializabilidade" (quando julgada válida) sem poder oferecer vitimização (julgada "justificável" ou não) como estratégia de produção de conhecimento?

\section{Agora uma história pessoal (com h minúsculo)}

Esforço-me em escrever linearmente, ou melhor, a conduzir os pensamentos não lineares num fio condutor linear. Vejo que esta forma de me expressar neste contexto tem o risco de ser um erro total. Arrisco-me, apesar disso, uma vez que vejo isso como sendo um pequeno pedaço de liberdade, tão raro e tão preciso. A linearidade pode ser uma bússola necessária para beneficiar a finalidade de comunicação com os interlocutores, mas pode igualmente ser um género de monstro autoritário de narração.

À procura da origem desta não-linearidade em mim encontra-se uma justificação de todos os tipos de narração não textual, incluindo o audiovisual enquanto reino completamente alheio ao textual que tem o potencial de legitimar a não-linearidade, mesmo podendo ser assim um subproduto de importância menor num contexto académico. Uma experimentação na etnografia visual oferece a tal zona especial, onde existe a legitimidade de todas as espécies de narração, de não-narração ou mesmo de um híbrido entre os dois pólos. Esta possibilidade implica responsabilidade: qualquer desvio deve ser apenas feito através de controlo muito cauteloso, para que este seja produzido dentro dessa possibilidade e que não deixe de fazer parte desta.

Actualmente sou um crente na omnipresença do auto-biográfico (e do auto-etnográfico) em qualquer forma de representação ou meio de comunicação, pelo que vejo o cinema - no seu mais amplo sentido, incluindo qualquer tipo de audiovisual - num território ou numa região que tanto necessita de reinventar uma identidade como um conformismo político, e a actuar numa área onde a procura do exotismo do desconhecido seja ainda permitida. Num tal contexto pós-colonial onde a língua do antigo administrador coexiste oficialmente com a do antigo administrado - agora o novo administrador - e onde tem ainda um peso na construção identitária, para ter consciência de uma identidade através de um exotismo doméstico e temporal até nem é necessário deixar fisicamente Macau.

O acto de querer aprender a língua do antigo administrador não era algo tão encorajado como é hoje: quis aprender o português na Universidade da minha terra como primeira e única opção, mesmo sabendo que era uma das licenciaturas que exigiam menos pontos no exame de admissão. O meu único projecto era compreender o que era Macau, consultando documentos históricos. As produções cinematográficas locais feitas na mesma época que as minhas pretendem servir o território ou região, com algumas excepções que chegam aos quatro cantos do mundo. A necessidade de aprender a língua não foi a de servir o prazer capitalista que o cinema poderia trazer, mas antes a de o usar como meio poderoso que me dava o direito de falar e criticar os problemas publicamente..

Concentrando-me nas minhas produções e julgando-as, admito que o valor cinematográfico destas seja praticamente inexistente. A única utilidade destas produções é a de poderem servir como testemunho 
da evolução identitária da minha própria pessoa, que é aquilo que espero poder reflectir num contexto mais amplo. Ao rever a minha escassíssima filmografia, vejo um trajecto que começou pela defesa crítica da identidade, passando por uma euforia da riqueza do património, e até uma excentricidade ao retirar-me do território político físico existente.

O turbilhão emocional-intelectual produzido na minha formação ocidental de antropologia visual ainda não está completamente transformado numa fonte de criação: vejo um grande contraste entre dois mundos intelectuais paralelos que servem dois objectivos diferentes. Passo a ilustrar, comparando as minhas próprias produções antes e depois da referida formação: Euforia vs. Vitimização; Local vs. Universal; Material vs. Ideias.

O contraste mais importante é para quem e com que fim eu sirvo. Por um lado, devo servir para participar na criação colectiva e eufórica de uma identidade enquanto um jovem feliz; por outro lado, devo servir a descolonização da academia ocidental ao vitimizar-me enquanto antigo colonizado. No meu caso, e no de outros jovens de Macau da mesma época, aparentemente, como jovens felizes, gozamos do luxo de uma vida abundante sem sermos obrigados a reflectir sobre a brutalidade "clássica" de uma colónia, porque tal, como mencionado, não aconteceu no nosso caso.

\section{Uma nota final}

Consciente da natureza deste texto, independentemente da qualidade que o mesmo tenha em vários campos, dou-me muito claramente conta de que participo, enquanto um legítimo "cúmplice", da criação e desenvolvimento do tema no presente ensaio. Sofri, igualmente, os conflitos e dilemas em mim existentes ao redigi-lo: o conflito entre dirigir-me a um público mais geral, apesar do âmbito académico, e procurar imitar o que compreendi da escrita de Gayatri Chakravorty Spivak ou de Trinh T. Minh-ha. Por fim, quando folheei de novo os livros daqueles autores anos depois da primeira leitura, enquanto leitor muitíssimo longínquo em todos os termos, percebi que inventei as minhas próprias versões de Spivak ou Trinh.

O dilema provém da minha luta em defesa de uma escrita própria, mesmo que caótica e algo incompreensível, e que pode parecer mais uma constelação de palavras forçadas num aparente artigo linear. Contudo, ouvida uma pessoa muito amável e simpática que me tem dado conselhos de escrita para a revisão de artigos para um jornal onde publico, aceito uma posição de compromisso, fazendo o meu melhor para não "descarrilar" demasiado...

De novo, não vejo a necessidade de repetir as minhas próprias palavras que escrevi mas que penso poder incorporar neste ensaio, "Macau e as fronteiras que ainda existem" (2021) ou "A nostalgia na fotografia" (2021). Apenas gostaria de reiterar que percebo muito bem que, ao escrever, estou também a fabricar uma nostalgia, três décadas antes de 2049. Ao fabricar esta nostalgia própria num maior contexto de "nostalgização", apresentei aqui uma monstruosa tentativa de contar uma história com um mínimo de factos e uma linearidade forçada, na esperança de fazer com que um tema de importância menor fique visível.

\section{Anexo: Filmografia do autor.}

\section{Narrador do episódio da série de documentários “歷史足印” sobre a Capitania dos Portos, 2005}

Para além de várias entrevistas televisivas enquanto membro e, por um período muito breve, presidente da Associação de História da Escola Pui Tou em Macau, participei enquanto operador de câmara na gravação da entrevista que Ma Man Kei, falecido patriota, homem de negócios de Macau e antigo vice-presidente do Conferência Consultiva Política do Povo Chinês, (1919-2014) concedeu a um projecto de história oral de Macau. Mas foi quando fui convidado para narrar um episódio do documentário sobre a Capitania dos Portos, com o livro "Histórias da Arquitectura de Macau" (2005), que co-editei, que tive o primeiro contacto com produção de documentários.

O conteúdo deste episódio baseia-se no referido livro, com duração de oito minutos, e foi produzido pela Televisão Educativa de Macau. A minha narração foi sobre a origem da antiga Capitania dos Portos, hoje transformada na Direcção dos Serviços de Assuntos Marítimos e de Água, e também participei nas filmagens. O documentário está em cantonense e no YouTube existe uma versão legendada em francês elaborada por mim.

\section{https://youtu.be/zDx965R-nfU}

\section{Produtor de "As Fontes de Água de Macau", 2007, 2008}

Três anos antes de uma estreita colaboração com Season Lao, artista de Macau, na produção de documentários sobre Macau, fiz várias traduções do chinês mandarim-cantonense para português para os seus projectos, incluindo um vídeo que foi exibido em 2006 numa das mais antigas associações de trabalho audiovisual, "Cut", no evento "Tales, Images, Photo and Your Mouth".

Incentivado com a ideia de concorrer a um financiamento do Instituto Cultural e aspirando a produzir documentários críticos sob a influência da Radio Television Hong Kong (RTHK), propus a Lao a produção de um documentário baseado num artigo que publiquei sobre "As Fontes de Água de Macau", o meu primeiro trabalho publicado (em chinês mandarim) durante os meus estudos portugueses (2005-2010). 
O documentário elaborado em colaboração com Lao foi aceite para o Festival Internacional de Cinema e Vídeo de Macau. À procura da "origem" dos luso-descendentes como um "exotismo" doméstico para reflectir a nossa própria identidade enquanto residentes naturais de Macau e de expressão cantonense, entrevistámos o escritor lusófono mais proeminente a nível local, Henrique de Senna Fernandes (1923-2010), o historiador Jorge Cavalheiro, o arquiteto Francisco Vizeu Pinheiro e o historiador Lam Fat lam, constituindo o resultado um raro exemplo de documentário bilíngue após a transferência de poderes de Macau em 1999. A primeira versão mais curta do documentário foi exibida publicamente na antiga Biblioteca Internacional da Universidade de Macau, em 2007, e foi uma inabitual voz crítica sobre património, já na altura classificado pela UNESCO, e abandonado. A versão mais longa, com duração de 30 minutos, teve estreia naquele festival em 2008.

\section{https://vimeo.com/117691016}

\section{Co-autor do guião de "Páteo do Mungo", 2008}

O documentário "Páteo do Mungo" teve também o objectivo de defender várias casas cantonenses naquele pátio que estavam em risco de serem demolidas e sem estatuto de património classificado. Interessante foi observar como tive consciência, após um documentário sobre o património lusófono, da necessidade de defender também o património e a história da comunidade de expressão cantonense.

\section{https://vimeo.com/113497271}

\section{Autor de "Ou Mun Ian, Macaenses - 35 Entrevistados, 35 Identidades", 2009}

Este documentário, através do qual procurei compreender a questão identitária de Macau, tem duas versões: uma versão de cerca de um quarto de hora realizada por Season Lao e uma outra versão realizada por mim e que tem duração de 34 minutos. Com uma narração de estilo "Deus omnipresente" em cantonense, o meu documentário tem, curiosamente, uma repartição da duração que considero muito interessante: cinco minutos de narração sobre a história identitária de Macau, dez minutos com entrevistas em cantonese, dez minutos com entrevistados em português e cinco minutos do conteúdo fornecido pelos informantes anglófonos. Fiquei surpreendido ao perceber, passados mais de dez anos após a produção, pois tal não foi planeado, que os minutos das respectivas entrevistas em diferentes línguas, curiosamente, correspondem linguisticamente à "exatidão política" da realidade de Macau.

Escrevi uma reflexão, publicada igualmente em Avanca, sobre o documentário, "Une identité réinterprétée: Notes sur un vieux documentaire et recherche[s] autour de l'identité macanaise" (2020). Duas das apresentações mais importantes do documentário foram moderadas e co-apresentadas em 2010 por Ana Maria Amaro, falecida antropóloga portuguesa e especialista em Macau que consultei e que teve a gentileza de me conceder uma entrevista.

\section{https://vimeo.com/112943097}

\section{Autor de “Uma Ficção Inútil”, 2014/5}

Já apresentei em diversas ocasiões esta etnografia visual experimental, tanto no contexto académico, como noutros tipos de eventos como festivais de cinema, em 40 países. O guião comentado (2017), em inglês, de "Uma Ficção Inútil" é uma versão melhorada do trabalho final do mestrado em antropologia visual e dos media na Universidade Livre de Berlim, e elaborei uma outra reflexão (2019), também em inglês, igualmente publicada num contexto académico.

A curta-metragem experimental foi uma reação minha ao conhecimento ocidental em geral, e sobretudo à antropologia visual.

Não abordo neste texto o conteúdo das diversas discussões ao redor do filme, mas refiro somente o que mencionei no texto principal do ensaio: este filme foi o trabalho final do mestrado em antropologia visual enquanto, na minha compreensão, uma formação ocidental com o fim de formar antigos colonizados ao serviço da descolonização pelo Ocidente. Isso trouxe uma transição importante que me marcou enormemente enquanto "mediador de culturas" e trouxe-me até aqui para defender o valor de estudos sobre Macau fora da sua geografia e para defender igualmente a sua visibilidade internacional.

https://vimeo.com/111432371

\section{Outros items}

Para além dos filmes acima referidos, fiz um vídeo experimental "A Etimologia de um Sonho" (2020) que foi exibido na Poznań Art Week em 2020 e ainda tenho um projecto de documentário incompleto sobre Henrique de Senna Fernandes.

Fui também assistente de produção e de montagem numa série de documentários, "The Colours of China", para a empresa de produção alemã "Gebrueder beetz filmproduktion", entre 2018 e 2019.

Cheong Kin Man is a Macau born-and-raised visual anthropologist. He was active in Macau historical research since high school and throughout his BA studies, and co-published several books. One of his early documentaries "Ou Mun lan, Macaenses" (2009) inspired his BA thesis in Portuguese studies which won a distinction at Macau's "Young Researcher Award" in 2010. In 2013 he left his government translator position, and one year later finished a film for his MA studies in visual anthropology, "A Useless Fiction", with 
international success. He is now a PhD student in the same field at the Freie Universität Berlin.

\section{Agradecimento}

O autor expressa o seu sincero agradecimento a Ana Dias, Jorge Veiga Alves e Maria João Caetano pelas suas preciosas sugestões a fim de melhorar a redação em língua portuguesa deste ensaio. No entanto, o autor assume a total responsabilidade pelo conteúdo.

\section{Bibliography}

Cheong, Kin Man, Schmidt, Charlotte, 2020. "Dekolonialisierung des Undekolonialisierbaren durch Bewegtbild: Macau", in matices 101:28-31.

Cheong, Kin Man, 2020. "Une identité réinterprétée: Notes sur un vieux documentaire et recherche[s] autour de l'identité macanaise" in AVANCA | CINEMA 2020, 18-22.

Cheong, Kin Man, 2021. "Macau e as fronteiras que ainda existem", "Extramuros". https://www.extramuros. net/2021/01/14/macau-e-as-fronteiras-que-ainda-existem/ Last access on 20/4/2021.

Cheong, Kin Man, 2021. "A nostalgia na fotografia", "Extramuros". https://www.extramuros.net/2021/03/10/anostalgia-na-fotografia/ Last access on 20/4/2021. 